Article

\title{
Multi-Material Additive Manufacturing of Sustainable Innovative Materials and Structures
}

\author{
Rupinder Singh ${ }^{1} \mathbb{D}$, Ranvijay Kumar ${ }^{1}$, Ilenia Farina ${ }^{2, *}{ }^{\text {, Francesco Colangelo }}{ }^{2}$, Luciano Feo ${ }^{3}$ \\ and Fernando Fraternali ${ }^{3, *}$ \\ 1 Department of Production Engineering, Guru Nanak Dev Engineering College, Ludhiana 141006, India; \\ rupindersingh78@yahoo.com (R.S.); ranvijayk12@gmail.com (R.K.) \\ 2 Department of Engineering, University of Naples Parthenope, 80143 Naples, Italy; \\ francesco.colangelo@uniparthenope.it \\ 3 Department of Civil Engineering, University of Salerno, 84084 Fisciano (SA), Italy; 1.feo@unisa.it \\ * Correspondence: ilenia.farina@uniparthenope.it (I.F.); f.fraternali@unisa.it (F.F.)
}

Received: 18 November 2018; Accepted: 27 December 2018; Published: 4 January 2019

check for updates

\begin{abstract}
This paper highlights the multi-material additive manufacturing (AM) route for manufacturing of innovative materials and structures. Three different recycled thermoplastics, namely acrylonitrile butadiene styrene (ABS), polylactic acid (PLA), and high impact polystyrene (HIPS) (with different Young's modulus, glass transition temperature, rheological properties), have been selected (as a case study) for multi-material AM. The functional prototypes have been printed on fused deposition modelling (FDM) setup as tensile specimens (as per ASTM D638 type-IV standard) with different combinations of top, middle, and bottom layers (of ABS/PLA/HIPS), at different printing speed and infill percentage density. The specimens were subjected to thermal (glass transition temperature and heat capacity) and mechanical testing (peak load, peak strength, peak elongation, percentage elongation at peak, and Young's modulus) to ascertain their suitability in load-bearing structures, and the fabrication of functional prototypes of mechanical meta-materials. The results have been supported by photomicrographs to observe the microstructure of the analyzed multi-materials.
\end{abstract}

Keywords: multi-material printing; fused deposition modelling; tensile properties; thermal properties; mechanical meta-materials

\section{Introduction}

Today, additive manufacturing (AM) has become one of the most common techniques for fabricating periodic lattices and innovative materials [1,2]. Commercially, many fabrication methods are available, with variable resolutions, including: polyjet 3-D printing; fused deposition modelling (FDM), selective laser sintering (SLS); electron beam melting (EBM); laser lithography; and projection microstereolithography etc. [3-11].

FDM is one of the low-cost techniques of AM which is used to prepare the functional prototypes of polymers/composites [12-17]. In FDM, parts are built layer by layer by heating a thermoplastic filament to a semi-liquid state and extruding it through a small nozzle per 3D CAD models in STL format $[18,19]$. The filament is usually $1.75 \mathrm{~mm}$ to $3.0 \mathrm{~mm}[20]$.

The reported literature highlights that the next generation structures using existing materials via AM will surely need to revolve around cost reduction, improved performance, and advanced structural design [21]. The study conducted for 3D printing of multilateral components of ABS and thermoplastic polyurethane (TPU) reveals, with support of 3D imaging, that interface properties are found in control with good layer connectivity [22]. Multi-material 3D printing potential is going to be a milestone in rapid manufacturing, customized design, and structural applications. Being compatible with 
functionally graded materials in a single structural form, multi-material 3D printing can potentially be applied in structural engineering applications to get the benefit of combined/hybridized material properties. Multi-material printing provides fast and robust structures with the functionality of all the combined materials $[23,24]$. It was suggested that the hybrid manufacturing (additive+ subtractive) process can fulfill the demand of high dimensional accuracy, less post-processing, and improved surface properties [25]. Multi-material 3D printing is applicable to new smart 4D structures which can provide specific shape/properties/functionalities [26]. It was highlighted that existing AM techniques, such as FDM, can be modified to hybrid deposition manufacturing (HDM) with embedded components to produce more complex, integrated multi-material components than with traditional techniques [27]. It was reported that build orientation, fabrication parameters, and associated variables can largely affect the connection between the multilateral interfaces during 3D printing [28,29], so these should be optimized to get better mechanical, thermal, and surface properties [30,31].

ABS is a common thermoplastic which is amorphous in nature and has high impact resistance, heat resistance, toughness, and low thermal conductivity with potential application in civil engineering. Generally, two types of ABS are classified: one as ABS for molding and another as ABS for extrusion/printing [32,33]. PLA exhibits a range of crystallinity and mechanical properties between polystyrene and polyethylene terephthalate. The bio-degradability and bio-compatibility are the key advantages of PLA to promote its use in the structural and bio-medical applications [34,35]. 'HIPS' is a low-cost polymer which provides ease of fabrication and machining. HIPS has low tensile strength, high impact strength (useful for structural application) when it is required to have low cost impact strength, machinability, and fabrication. It is commercially used in pre-production of prototypes because of its high dimensional stability and ease of fabrication, painting, and joining.

The reported literature reveals that many studies have been performed in the recent past to enhance the properties of thermoplastics by reinforcing them with metals/non-metals through extrusion and finally 3D printing by FDM $[12,13,18,19]$. But, hitherto, very little has been reported on multi-material printing of thermoplastics to enhance its mechanical properties. Since FDM is one of the cost-effective techniques for printing multi-material components, effort has been made to explore the effect of multi-material printing through FDM for preparation of functional prototypes which may be directly installed for structural applications (e.g., as a light load-bearing element) or next-generation mechanical meta-materials. This paper is an extension of work reported by Singh et al. [20], in which break properties were explored to understand the mechanism of failure in the case of multi-material components. In the present study, peak load properties supported by photomicrographs have been explored to understand the multi-material distribution behavior (in form of multi layers) in the3D printing of functional prototypes. In the present study, ABS, PLA, and HIPS were 3D-printed in multi-nozzle FDM to explore the applicability of the final products in structural applications.

\section{Materials and Methods}

ABS has high toughness, a high degree of moldability, and low thermal conductivity. PLA has good biodegradability/crystallinity. HIPS is low-cost with high impact resistance. These three recycled thermoplastics have been selected for the fabrication/multi-material printing operation with FDM. Table 1 shows the mechanical, thermal, and rheological properties of the feedstock materials (average and standard deviation values for three sets of observations). It should be noted that ABS, PLA, and HIPS have significant differences in their MFI, glass transition temperature, peak load, peak strength, peak elongation, Young's modulus, and yield stress. The aim of the present study is to fabricate the new part with three combined polymeric layers so that the final product possesses the advantages of all the polymers. 
Table 1. Properties of ABS, PLA, and HIPS.

\begin{tabular}{|c|c|c|c|c|c|c|c|c|c|}
\hline \multirow{2}{*}{ Polymers } & \multicolumn{3}{|c|}{ HIPS } & \multicolumn{3}{|c|}{ ABS } & \multicolumn{3}{|c|}{ PLA } \\
\hline & OV & SD & SEx & OV & SD & SEx & OV & SD & 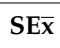 \\
\hline MFI (g/10 min) & $7.5 \pm 0.20$ & 0.16 & 0.11 & $8.76 \pm 0.16$ & 0.13 & 0.09 & $13.52 \pm 0.11$ & 0.09 & 0.06 \\
\hline Young's modulus (MPa) & $112.5 \pm 0.12$ & 0.09 & 0.06 & $175 \pm 0.11$ & 0.09 & 0.06 & $47.9 \pm 0.10$ & 0.08 & 0.05 \\
\hline Yield stress (MPa) & $3.44 \pm 0.21$ & 0.17 & 0.12 & $0.49 \pm 0.21$ & 0.17 & 0.12 & $0.27 \pm 0.16$ & 0.13 & 0.09 \\
\hline Glass transition temp $\left({ }^{\circ} \mathrm{C}\right)$ & $100.41 \pm 0.16$ & 0.13 & 0.09 & $109.76 \pm 0.2$ & 0.16 & 0.11 & $62.57 \pm 0.21$ & 0.17 & 0.12 \\
\hline Peak load (N) & $80.8 \pm 0.11$ & 0.08 & 0.06 & $207 \pm 0.2$ & 0.16 & 0.11 & $282.4 \pm 0.20$ & 0.16 & 0.11 \\
\hline Peak strength (MPa) & $4.21 \pm 0.16$ & 0.13 & 0.09 & $10.78 \pm 0.11$ & 0.09 & 0.06 & $14.71 \pm 0.16$ & 0.13 & 0.09 \\
\hline Peak elongation (mm) & $1.9 \pm 0.20$ & 0.16 & 0.11 & $4.75 \pm 0.16$ & 0.13 & 0.09 & $5.13 \pm 0.16$ & 0.13 & 0.09 \\
\hline $\begin{array}{c}\text { Percentage elongation at } \\
\text { peak }(\%)\end{array}$ & $3.0 \pm 0.11$ & 0.09 & 0.06 & $6.0 \pm 0.15$ & 0.12 & 0.08 & \pm 0.10 & 0.08 & 0.05 \\
\hline
\end{tabular}

Note: $\mathrm{OV}=$ Observed value, $\mathrm{SD}=$ standard deviation, $\mathrm{SE \overline {x }}=$ Standard error of mean.

\section{Experimentation}

The experimentation stage consisted of the evaluation of melting and solidification characteristics, glass transition temperature determination, extrusion, and multi-material 3D printing.

\subsection{Differential Scanning Calorimetry (DSC)}

DSC is analytical tool for determination of thermal properties, including melting points, glass transition temperature, solidification temperature, degree of crystallinity, heat capacity rate, etc. These properties are defined under controlled continuous heating (endothermic reaction) and controlled continuous cooling (exothermic reaction). The endothermic reaction was carried at the heating rate of $+10^{\circ} \mathrm{C} / \mathrm{min}$ from $30{ }^{\circ} \mathrm{C}$ to $250{ }^{\circ} \mathrm{C}$, whereas the exothermic reaction was carried at $-10^{\circ} \mathrm{C} / \mathrm{min}$ from $250{ }^{\circ} \mathrm{C}$ to $30^{\circ} \mathrm{C}$.

\subsection{Extrusion by Twin Screw Extrusion (TSE)}

In the present case, extrusion with TSE was performed at $230{ }^{\circ} \mathrm{C}$ with a screw speed of $50 \mathrm{rpm}$ and an applied load of $10 \mathrm{~kg}$ to prepare the feedstock filaments. The extrusion parameters were fixed based on pilot experimentation. The TSE used in the present study can produce $1.75 \pm 0.05 \mathrm{~mm}$ diameter feedstock filaments with yield of $2-3 \mathrm{~m} / \mathrm{min}$ under $50 \mathrm{rpm}$ screw speed.

\subsection{D Printing}

Commercial open-source FDM setup (Make: Divide by Zero, Model 250i, Mumbai, India) configured with two nozzle heads was used for multi-material 3D printing. The static parameters for the fabrication of the combined parts were:

(i) Diameter of nozzle: $\Phi 0.3 \mathrm{~mm}$

(ii) Diameter of filament: $\Phi 1.75 \pm 0.05 \mathrm{~mm}$

(iii) Height of layer: $0.27 \mathrm{~mm}$

(iv) Default printing layers on the outer periphery: $3+3$ (by adjusting 3 top and 3 bottom layers)

(v) Fill pattern: Rectilinear

(vi) Perimeter speed: $30 \mathrm{~mm} / \mathrm{sec}$

(vii) Travel speed: $130 \mathrm{~mm} / \mathrm{sec}$

(viii) Extrusion temperature: $250{ }^{\circ} \mathrm{C}$

(ix) Print bed temperature: $55^{\circ} \mathrm{C}$

In the present case study three input parameters were varied for printing (see Table 2):

(i) Infill percentage: 60,80 and $100 \%$

(ii) Speed of printing: 50, 60 and $70 \mathrm{~mm} / \mathrm{sec}$. 
(iii) Printing material configuration

The multi-material printing was performed with a total of 12 layers (4 layers of each material, i.e., ABS, PLA, and HIPS). The multi-material printing configurations named as APH, PHA, and HAP mean:

APH: bottom 4 layers of ABS, middle 4 layers of PLA, and top 4 layers of HIPS

PHA: bottom 4 layers of PLA, middle 4 layers of HIPS, and top 4 layers of ABS

HAP: bottom 4 layers of HIPS, middle 4 layers of ABS, and top 4 layers of PLA

Figure 1 shows the 3D view of the benchmark/sample on the printing interface.

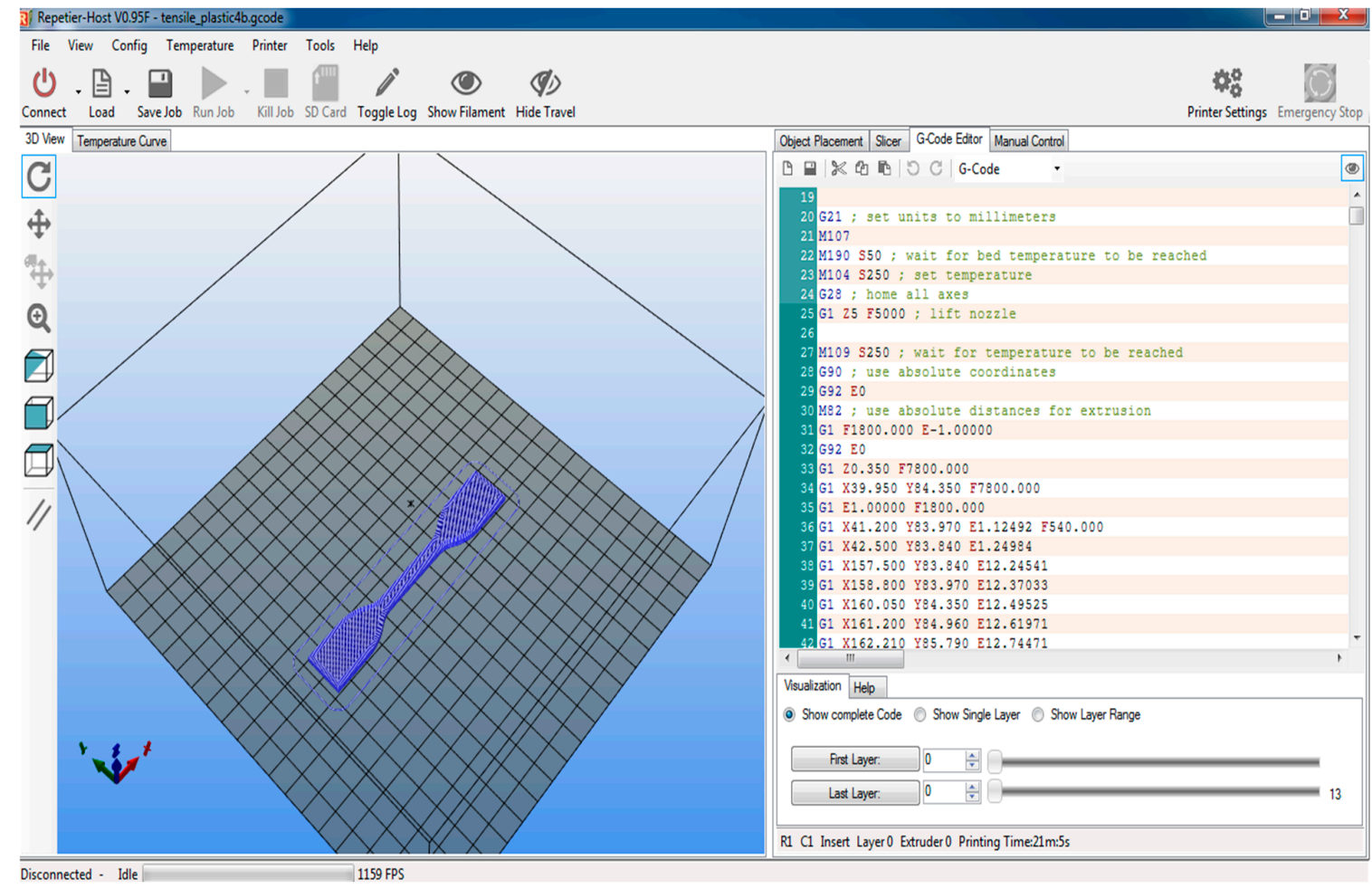

Figure 1. 3D benchmark of samples on the printing interface.

Based upon Table 2, 9 specimens (with three repetitions on each setting) of multi-material components were printed (as per Taguchi L9 orthogonal on commercial FDM setup as per ASTM D 638 type IV). The samples composed of single materials (ABS, PLA, and HIPS) were also printed with fixed parametric settings of FDM to analyze the changes in the mechanical strength and the interconnectivity of layers. Figure 2 shows the 3D-printed parts with multi-material layers.

Table 2. Input process variables for multi-material 3D printing on FDM.

\begin{tabular}{cccc}
\hline Parameters & Level 1 & Level 2 & Level 3 \\
\hline Material Combination & APH & PHA & HAP \\
Infill percentage (\%) & 60 & 50 & 100 \\
Printing Speed $(\mathbf{m m} / \mathbf{s e c})$ & 50 & 60 & 70 \\
\hline
\end{tabular}



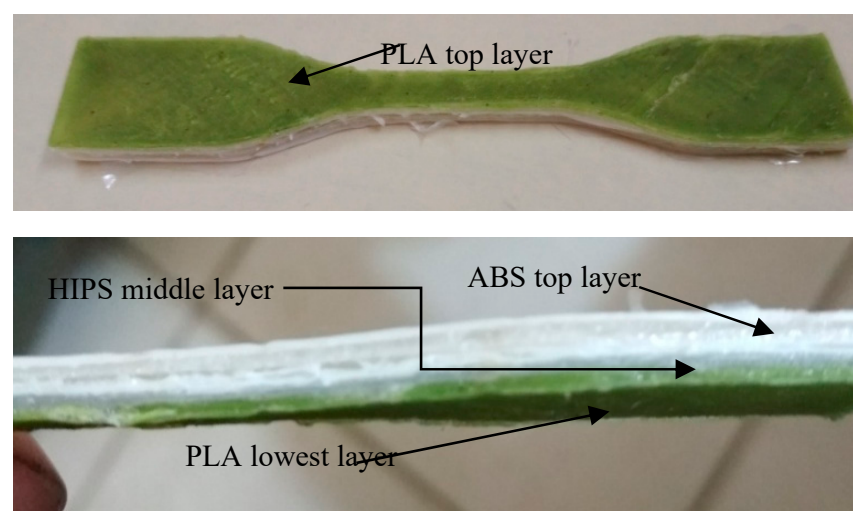

Figure 2. 3D-printed multi-material component of ASTM 638 type IV.

\section{Results and Discussion}

It was observed that the extruded feedstock of recycled ABS, PLA, and HIPS resulted in significant differences in mechanical properties. The experimental observations (average of three repeated trails) outlined that, as virgin material, ABS had the greatest Young's modulus, PLA had the greatest peak load, peak strength, peak elongation, and lowest Young's modulus and yield stress, whereas HIPS had the lowest peak load, peak elongation, peak strength, and greatest yield stress (See Table 1). Figure 3 shows the load vs. deflection curves of ABS, PLA, and HIPS materials under tensile failure.

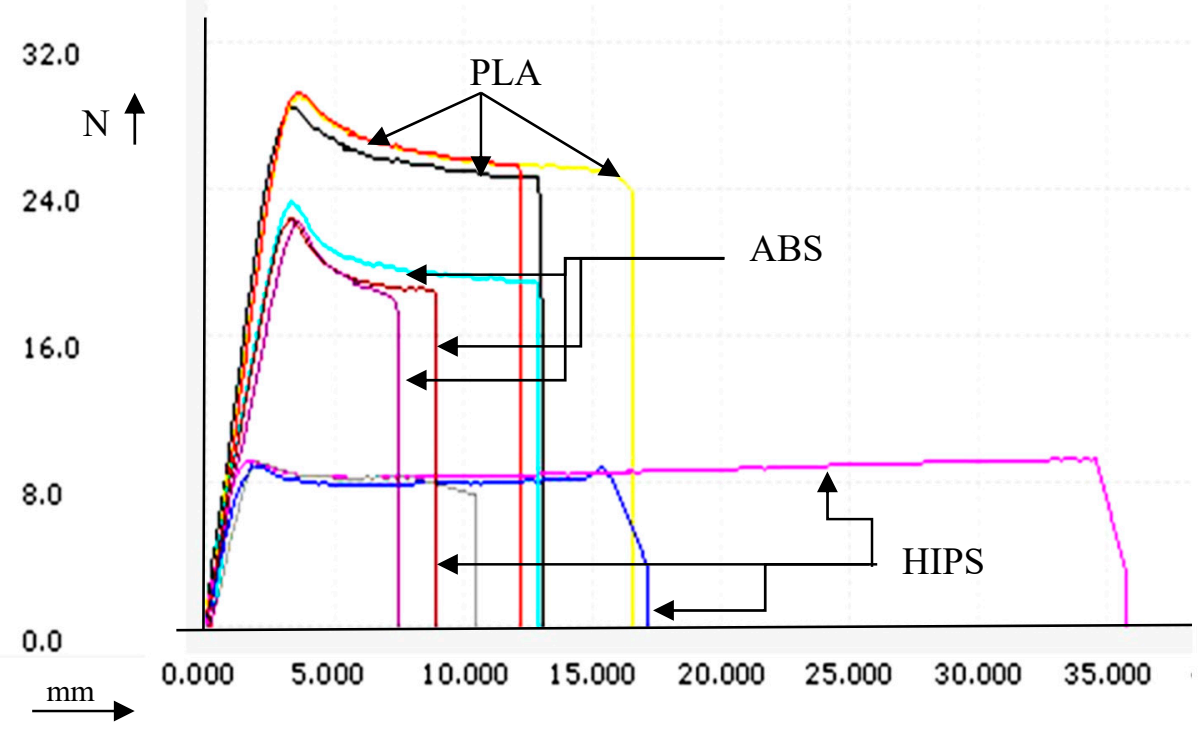

Figure 3. Load vs. deflection curve for extruded feedstock filaments.

As observed from Figure 3, the selected grade of PLA thermoplastic has the greatest peak load value (see Table 1), followed by ABS and HIPS. Hence, in multi-material structures, if PLA is selected for the outermost layer, followed by ABS (middle layer) and HIPS in the innermost section (especially in arch structures), this will lead to better stability from a load-bearing view point. Similar observations have been made by other investigators [36-38].

\subsection{Thermal Properties}

Figure 4 shows the DSC thermographs for ABS, PLA, and HIPS polymers. As observed from Figure 4, ABS, PLA, and HIPS are compatible with each other and have similar ranges of heat integral value. It has been observed that the integral heat input during heating of ABS, PLA, and HIPS 
was $13.63 \mathrm{~mJ}, 14.71 \mathrm{~mJ}$, and $11.71 \mathrm{~mJ}$, respectively. Thus, multi-material printing (with proposed combination) may result in better layer connectivity. On the other hand, during solidification of the material, it was observed that ABS, PLA, and HIPS released $13.52 \mathrm{~mJ}, 10.80 \mathrm{~mJ}$, and $10.87 \mathrm{~mJ}$ (which are also in similar range).

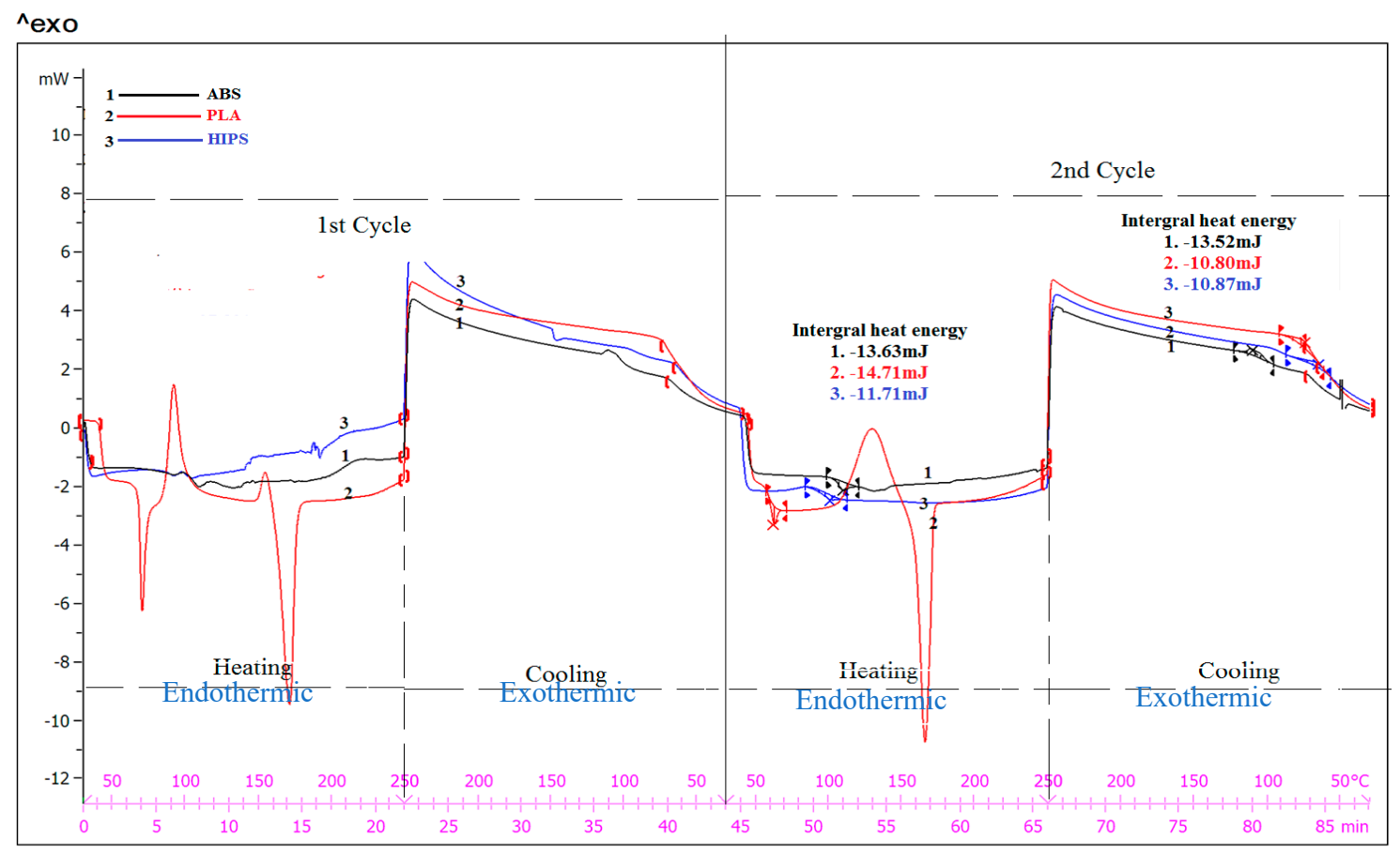

Lab: METTLER

$\mathrm{STAR}^{\odot} \mathrm{SW} 14.00$

Figure 4. DSC curves for ABS, PLA, and HIPS.

As shown in Figure 4, two heating and two cooling cycles were repeated and similar trends of the endothermic and exothermic reactions were observed. Hence, it is ascertained that under repetitive thermal shock, material integrity is not compromised (within the set temperature range). These results are also in line with the observations made otherwise [20].

\subsection{Tensile Properties}

The material was tested as per ASTM D 638 type IV (for 12 successive printed layers of ABS/HIPS/PLA) on a tensile testing machine. After the fracture of each sample, data were recorded (see Table 3). Three repetitions were made for each sample setting in order to reduce the experimental error. It was observed that in experiment no. 3 with the APH multi-material configuration, $100 \%$ infill percentage and $70 \mathrm{~mm} / \mathrm{sec}$ printing speed resulted in the greatest peak load, peak strength, and elongation properties and the lowest Young's modulus, whereas in experiment no. 1 with APH, the $60 \%$ infill and $50 \mathrm{~mm} / \mathrm{sec}$ printing speed configuration resulted in the lowest values of peak load, peak strength, and peak elongation properties. The component/prototype printed in experiment no. 4 had the greatest Young's modulus. The most important fact was observed in the case of the Young's modulus for experiments 2, 4, and 9, which resulted in values greater than those of any of the parent materials. Again, the yield stress in experiments 3, 8, and 9 resulted in the values below those of the parent materials. 
Table 3. Mechanical properties of 3D-printed multi-material components.

\begin{tabular}{|c|c|c|c|c|c|c|c|c|c|c|c|c|c|c|c|c|c|c|c|c|c|}
\hline \multirow{2}{*}{$\begin{array}{l}\text { Exp } \\
\text { No. }\end{array}$} & \multirow{2}{*}{$\begin{array}{c}\text { Material } \\
\text { Combination }\end{array}$} & \multirow{2}{*}{$\begin{array}{c}\text { Infill } \\
(\%)\end{array}$} & \multirow{2}{*}{$\begin{array}{l}\text { Printing } \\
(\mathrm{mm} / \mathrm{sec})\end{array}$} & \multicolumn{3}{|c|}{$\begin{array}{l}\text { Peak Load } \\
\text { (N) }\end{array}$} & \multicolumn{3}{|c|}{$\begin{array}{l}\text { Peak Strength } \\
\text { (MPa) }\end{array}$} & \multicolumn{3}{|c|}{$\begin{array}{c}\text { Peak Elongation } \\
(\mathrm{mm})\end{array}$} & \multicolumn{3}{|c|}{$\begin{array}{c}\text { Percentage Elongation at } \\
\text { Peak (\%) }\end{array}$} & \multicolumn{3}{|c|}{$\begin{array}{c}\text { Young's Modulus } \\
\text { (MPa) }\end{array}$} & \multicolumn{3}{|c|}{$\begin{array}{l}\text { Yield Stress } \\
\text { (MPa) }\end{array}$} \\
\hline & & & & OV & SD & SEX̄ & OV & SD & SEx & OV & SD & SEx & OV & SD & 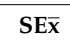 & OV & SD & SEX̄ & OV & SD & SEx \\
\hline 1 & $\mathrm{APH}$ & 60 & 50 & $\begin{array}{c}133.9 \pm \\
0.16\end{array}$ & 0.13 & 0.09 & $\begin{array}{c}6.97 \pm \\
0.20\end{array}$ & 0.16 & 0.11 & $\begin{array}{c}2.85 \pm \\
0.11\end{array}$ & 0.08 & 0.06 & $4 \pm 0.16$ & 0.13 & 0.09 & $\begin{array}{c}72.92 \pm \\
0.22\end{array}$ & 0.18 & 0.13 & $\begin{array}{c}2.73 \pm \\
0.21\end{array}$ & 0.17 & 0.12 \\
\hline 2 & APH & 50 & 60 & $\begin{array}{c}179.9 \pm \\
0.21\end{array}$ & 0.17 & 0.12 & $\begin{array}{c}9.37 \pm \\
0.11\end{array}$ & 0.08 & 0.06 & $\begin{array}{c}2.85 \pm \\
0.22\end{array}$ & 0.17 & 0.12 & $4 \pm 0.16$ & 0.13 & 0.09 & $\begin{array}{c}264.58 \pm \\
0.21\end{array}$ & 0.17 & 0.12 & $\begin{array}{c}2.68 \pm \\
0.16\end{array}$ & 0.13 & 0.09 \\
\hline 3 & $\mathrm{APH}$ & 100 & 70 & $\begin{array}{c}206.9 \pm \\
0.11\end{array}$ & 0.08 & 0.06 & $\begin{array}{c}10.78 \pm \\
0.12\end{array}$ & 0.09 & 0.06 & $\begin{array}{c}4.37 \pm \\
0.17\end{array}$ & 0.14 & 0.10 & $6 \pm 0.17$ & 0.13 & 0.09 & $\begin{array}{c}73.29 \pm \\
0.11\end{array}$ & 0.08 & 0.06 & $\begin{array}{c}0.21 \pm \\
0.20\end{array}$ & 0.16 & 0.11 \\
\hline 4 & PHA & 60 & 60 & $\begin{array}{c}161.3 \pm \\
0.21\end{array}$ & 0.17 & 0.12 & $\begin{array}{c}8.40 \pm \\
0.16\end{array}$ & 0.13 & 0.09 & $\begin{array}{c}3.04 \pm \\
0.20\end{array}$ & 0.16 & 0.11 & $4 \pm 0.22$ & 0.17 & 0.12 & $\begin{array}{c}325.00 \pm \\
0.12\end{array}$ & 0.09 & 0.06 & $\begin{array}{c}1.00 \pm \\
0.11\end{array}$ & 0.08 & 0.06 \\
\hline 5 & PHA & 80 & 70 & $\begin{array}{c}189.9 \pm \\
0.20\end{array}$ & 0.16 & 0.11 & $\begin{array}{c}9.89 \pm \\
0.12\end{array}$ & 0.09 & 0.06 & $\begin{array}{c}3.99 \pm \\
0.13\end{array}$ & 0.09 & 0.06 & $5 \pm 0.21$ & 0.17 & 0.12 & $\begin{array}{c}79.17 \pm \\
0.05\end{array}$ & 0.04 & 0.02 & $4.54 \pm 0.2$ & 0.08 & 0.05 \\
\hline 6 & PHA & 100 & 50 & $\begin{array}{c}187.9 \pm \\
0.11\end{array}$ & 0.08 & 0.06 & $\begin{array}{c}9.79 \pm \\
0.20\end{array}$ & 0.16 & 0.11 & $\begin{array}{c}3.23 \pm \\
0.12\end{array}$ & 0.09 & 0.06 & $4 \pm 0.1$ & 0.08 & 0.05 & $\begin{array}{c}108.33 \pm \\
0.12\end{array}$ & 0.09 & 0.06 & $\begin{array}{c}5.13 \pm \\
0.16\end{array}$ & 0.13 & 0.10 \\
\hline 7 & HAP & 60 & 70 & $\begin{array}{c}149.0 \pm \\
0.11\end{array}$ & 0.08 & 0.06 & $\begin{array}{c}7.76 \pm \\
0.22\end{array}$ & 0.17 & 0.12 & $\begin{array}{c}3.99 \pm \\
0.16\end{array}$ & 0.13 & 0.09 & $5 \pm 0.11$ & 0.08 & 0.06 & $\begin{array}{c}85.42 \pm \\
0.18\end{array}$ & 0.14 & 0.10 & $\begin{array}{c}0.28 \pm \\
0.11\end{array}$ & 0.08 & 0.06 \\
\hline 8 & HAP & 80 & 50 & $\begin{array}{c}174.8 \pm \\
0.16\end{array}$ & 0.13 & 0.09 & $\begin{array}{c}9.10 \pm \\
0.11\end{array}$ & 0.08 & 0.06 & $\begin{array}{c}3.42 \pm \\
0.12\end{array}$ & 0.08 & 0.06 & $5 \pm 0.21$ & 0.17 & 0.12 & $\begin{array}{c}161.84 \pm \\
0.12\end{array}$ & 0.08 & 0.06 & $\begin{array}{c}0.17 \pm \\
0.21\end{array}$ & 0.17 & 0.12 \\
\hline 9 & HAP & 100 & 60 & $\begin{array}{c}164.4 \pm \\
0.11\end{array}$ & 0.08 & 0.06 & $\begin{array}{c}8.56 \pm \\
0.16\end{array}$ & 0.13 & 0.09 & $\begin{array}{c}3.61 \pm \\
0.13\end{array}$ & 0.10 & 0.07 & $5 \pm 0.16$ & 0.13 & 0.09 & $\begin{array}{c}249.67 \pm \\
0.13\end{array}$ & 0.10 & 0.07 & $\begin{array}{c}0.16 \pm \\
0.16\end{array}$ & 0.13 & 0.09 \\
\hline
\end{tabular}


Based upon Table 3, Figure 5 shows a graphical representation of peak load vs. experiment number (error bars with standard error), which is well in 5\% range. Similar results have been attained for all other mechanical properties.

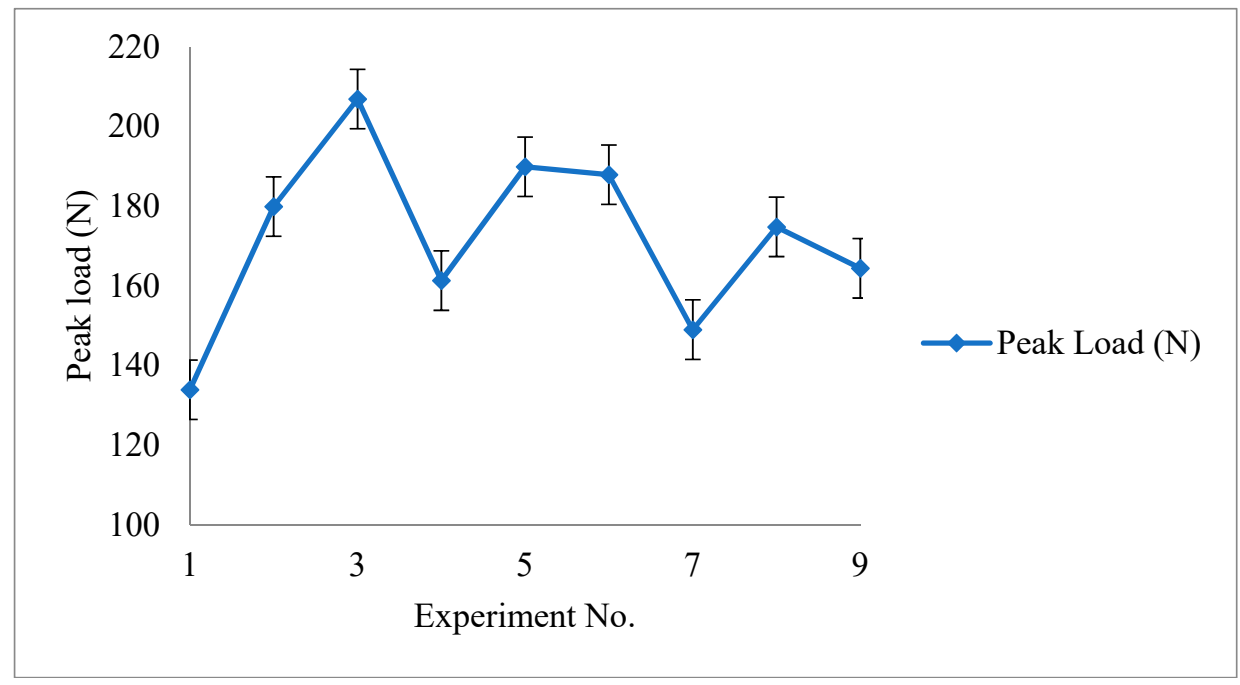

Figure 5. Peak load vs. experiment number (for calculation of standard error).

3D-printed parts with high part density must have high peak load and low strain values [36-38]. As observed from experiments 1-3 (Table 3) with material combination APH, the peak load values follow this behavior, but the peak elongation value at high density is greater, which is contrary to the general behavior. Also, the Young's modulus value in experiment 2 is higher compared to experiments 1 and 3 . This may be because of the fact that the multi-material printed functional prototype has compromised properties, i.e.in tensile loading conditions, the fusion pattern of one material layer on another material layer may have contributed to deviation in the physical-mechanical properties (which is dependent upon many input parameters, including printing speed, rheological properties, material combination, etc.). Similarly, comparing experiments 4-6, better Young's modulus was observed in experiment 4, whereas, while comparing experiments 7-9, better Young's modulus was observed in experiment 9. Further, based upon Table 3, Figure 6 shows the load vs. deflection curve for virgin/single printed material as well as multi-material functional prototypes. For better understanding of fused layer deposition, based upon Table 3, photomicrographs were observed with the help of a Mitutoyo Tool maker's microscope at $30 \times$ magnification (see Figure 7). As observed from Figure 7, the single-material printed geometry of ABS, PLA, and HIPS prototypes showed uniform layer orientation, tightly stacked layers, whereas in the case of multi-material prototypes, the uniformity of the layers was compromised. It should be noted that the greatest values of peak load, peak elongation, and peak strength measured by pull out test were achieved in experiment 6 (PHA, $100 \%$ infill percentage, and $50 \mathrm{~mm} / \mathrm{sec}$ printing speed). From photomicrographs of the part printed in experiment 6 , it is clear that the layers are tightly stacked and uniformity is maintained (similar to single-material). In the case of experiment 1 where peak load and peak strength had worse values than each single/parent material, the layers were not uniformly packed (See Figure 7). 


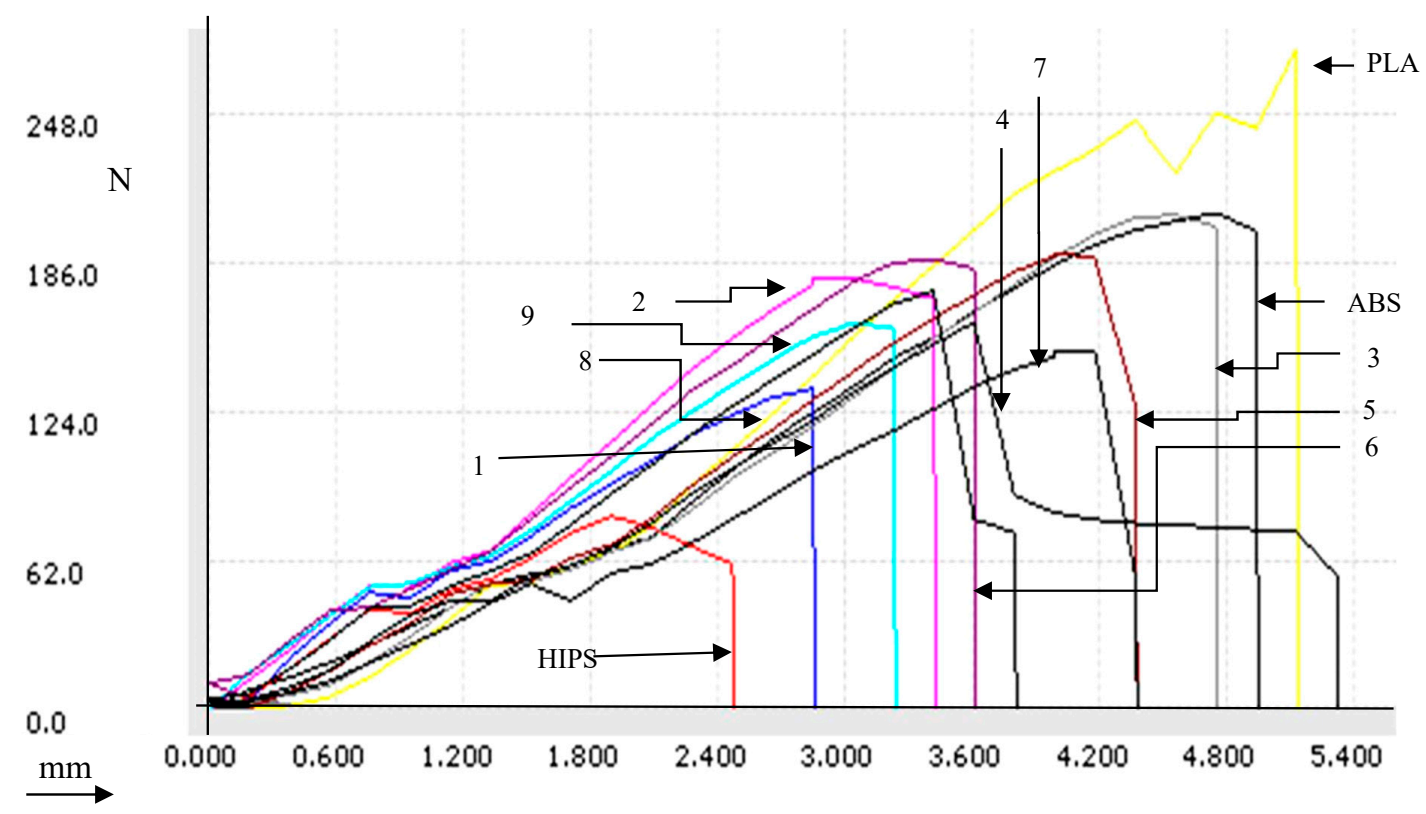

Figure 6. Load vs. deflection curve for tensile fractured components.
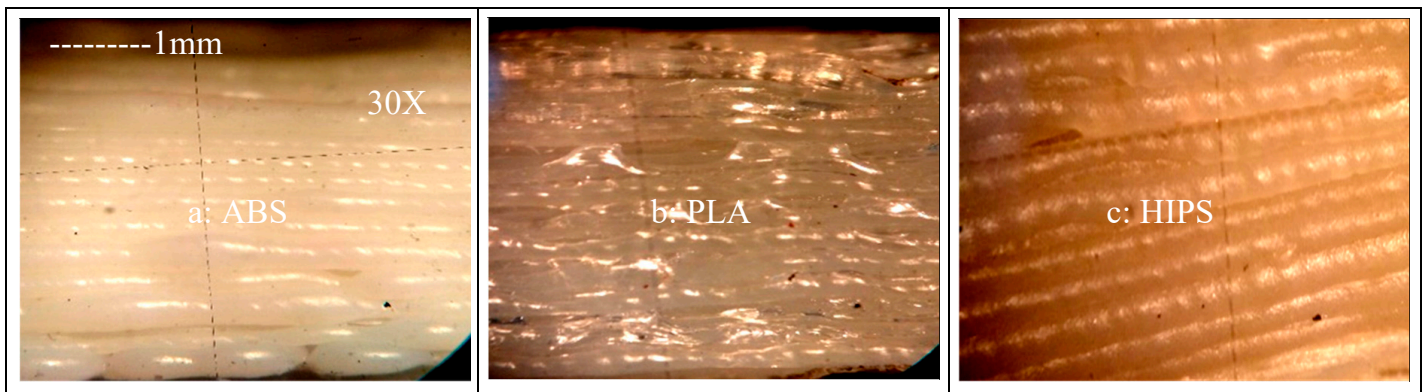

Single material 3D-printed samples (a: ABS, b: PLA, c: HIPS)
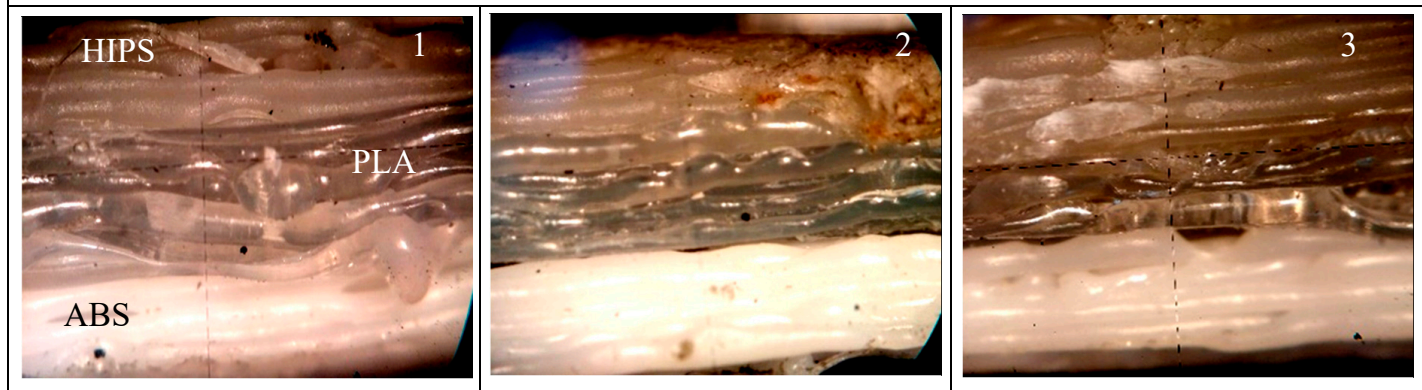

Multi-material 3D-printed samples (Top layer HIPS, middle layer PLA and bottom layer ABS)
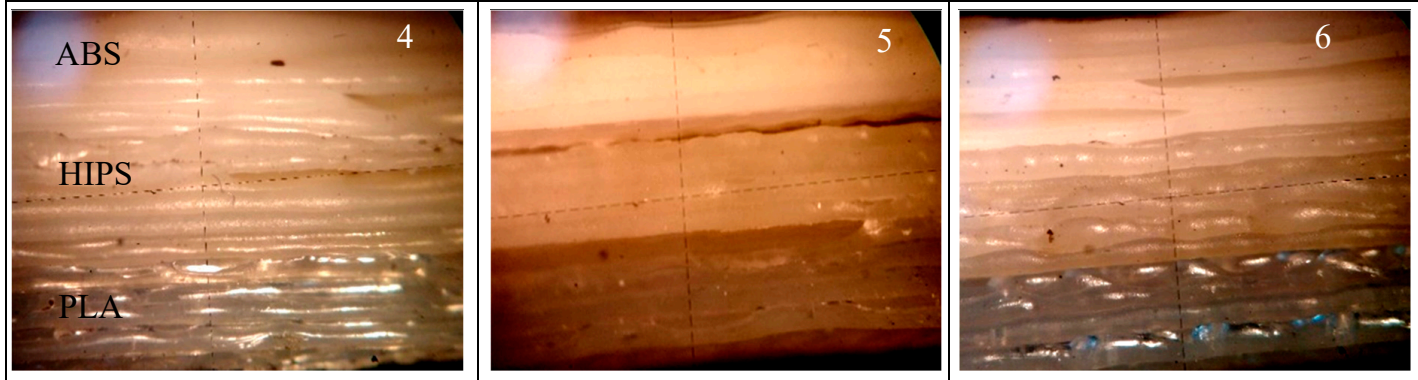

Multi-material 3D-printed samples (Top layer ABS, middle layer HIPS and bottom layer PLA)

Figure 7. Cont. 

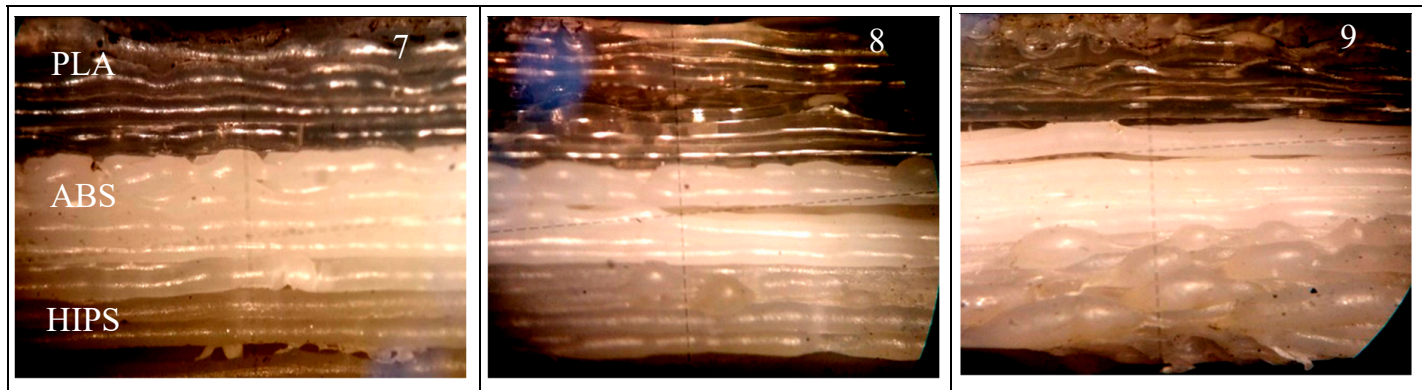

Multi-material 3D-printed samples (Top layer PLA, middle layer ABS and bottom layer HIPS)

Figure 7. Micrographic observations at $30 \times$ magnification with a Tool maker microscope.

\subsection{Pull-Out Test}

Pull-out testing is one of the most important considerations for structural applications. The pull-out test was conducted (using the material combinations in Table 3) on all the samples to evaluate the peak load, peak strength, peak elongation, and percentage changes of peak elongation. It was observed that samples 3 and 6 resulted in values of peak load, peak strength greater than HIPS but significantly lower than ABS and PLA. In experiment6, the value of peak elongation resulted in values greater than all the single/parent materials (see Table 4).

Table 4. Pull-out properties of 3D-printed components.

\begin{tabular}{|c|c|c|c|c|c|c|c|c|c|c|c|c|}
\hline \multirow{2}{*}{$\begin{array}{l}\text { Experiment } \\
\text { no. }\end{array}$} & \multicolumn{3}{|c|}{$\begin{array}{l}\text { Peak Load } \\
\text { (kgf) }\end{array}$} & \multicolumn{3}{|c|}{$\begin{array}{l}\text { Peak Strength } \\
\left(\mathrm{kg} / \mathrm{mm}^{2}\right)\end{array}$} & \multicolumn{3}{|c|}{$\begin{array}{l}\text { Peak Elongation } \\
(\mathrm{mm})\end{array}$} & \multicolumn{3}{|c|}{$\begin{array}{c}\text { Percentage Elongation at } \\
\text { Peak }(\%)\end{array}$} \\
\hline & OV & SD & SEx & OV & SD & SEx & OV & SD & SEx & OV & SD & SEx \\
\hline 1 & $52.8 \pm 0.15$ & & & $14.83 \pm 0.16$ & 0.13 & 0.09 & $3.23 \pm 0.10$ & & & $2 \pm 0.15$ & 0.12 & 0.08 \\
\hline 2 & $80.1 \pm 0.16$ & 0.13 & 0.09 & $22.49 \pm 0.12$ & 0.09 & 0.06 & $4.37 \pm 0.16$ & 0.13 & 0.09 & $2 \pm 0.15$ & 0.12 & 0.08 \\
\hline 3 & $100.7 \pm 0.11$ & 0.08 & 0.06 & $28.27 \pm 0.12$ & 0.09 & 0.06 & $4.18 \pm 0.12$ & 0.09 & 0.06 & $2 \pm 0.10$ & 0.08 & 0.06 \\
\hline 4 & $75.4 \pm 0.11$ & 0.08 & 0.06 & $21.17 \pm 0.21$ & 0.17 & 0.12 & $4.18 \pm 0.06$ & 0.04 & 0.03 & $2 \pm 0.20$ & 0.16 & 0.11 \\
\hline 5 & $86.2 \pm 0.11$ & 0.08 & 0.06 & $24.2 \pm 0.21$ & 0.17 & 0.12 & $4.18 \pm 0.16$ & 0.13 & 0.09 & $2 \pm 0.10$ & 0.08 & 0.06 \\
\hline 6 & $102.6 \pm 0.21$ & 0.17 & 0.12 & $28.81 \pm 0.11$ & 0.08 & 0.06 & $4.56 \pm 0.11$ & 0.08 & 0.06 & $2 \pm 0.10$ & 0.08 & 0.06 \\
\hline 7 & $54.7 \pm 0.16$ & 0.13 & 0.09 & $15.36 \pm 0.17$ & 0.14 & 0.09 & $2.85 \pm 0.16$ & 0.13 & 0.09 & $1 \pm 0.20$ & 0.16 & 0.12 \\
\hline 8 & $83.6 \pm 0.11$ & 0.08 & 0.06 & $23.47 \pm 0.21$ & 0.17 & 0.12 & $3.99 \pm 0.21$ & 0.17 & 0.12 & $2 \pm 0.10$ & 0.08 & 0.06 \\
\hline 9 & $77.4 \pm 0.16$ & 0.13 & 0.09 & $21.73 \pm 0.22$ & 0.18 & 0.13 & $2.28 \pm 0.16$ & 0.13 & 0.09 & $1 \pm 0.15$ & 0.12 & 0.08 \\
\hline ABS & $129.5 \pm 0.20$ & 0.16 & 0.11 & $36.36 \pm 0.17$ & 0.14 & 0.09 & $3.99 \pm 0.11$ & 0.08 & 0.06 & $2 \pm 0.15$ & 0.12 & 0.08 \\
\hline PLA & $172.6 \pm 0.21$ & 0.17 & 0.12 & $48.46 \pm 0.22$ & 0.18 & 0.13 & $4.37 \pm 0.23$ & 0.18 & 0.13 & $2 \pm 0.20$ & 0.16 & 0.11 \\
\hline HIPs & $97.6 \pm 0.12$ & 0.09 & 0.06 & $27.4 \pm 0.11$ & 0.08 & 0.06 & $2.28 \pm 0.23$ & 0.18 & 0.13 & $1 \pm 0.20$ & 0.16 & 0.11 \\
\hline
\end{tabular}

Based upon Table 4, Figure 8 shows the load vs. deflection curves for of the 3D-printed multi-material components. 


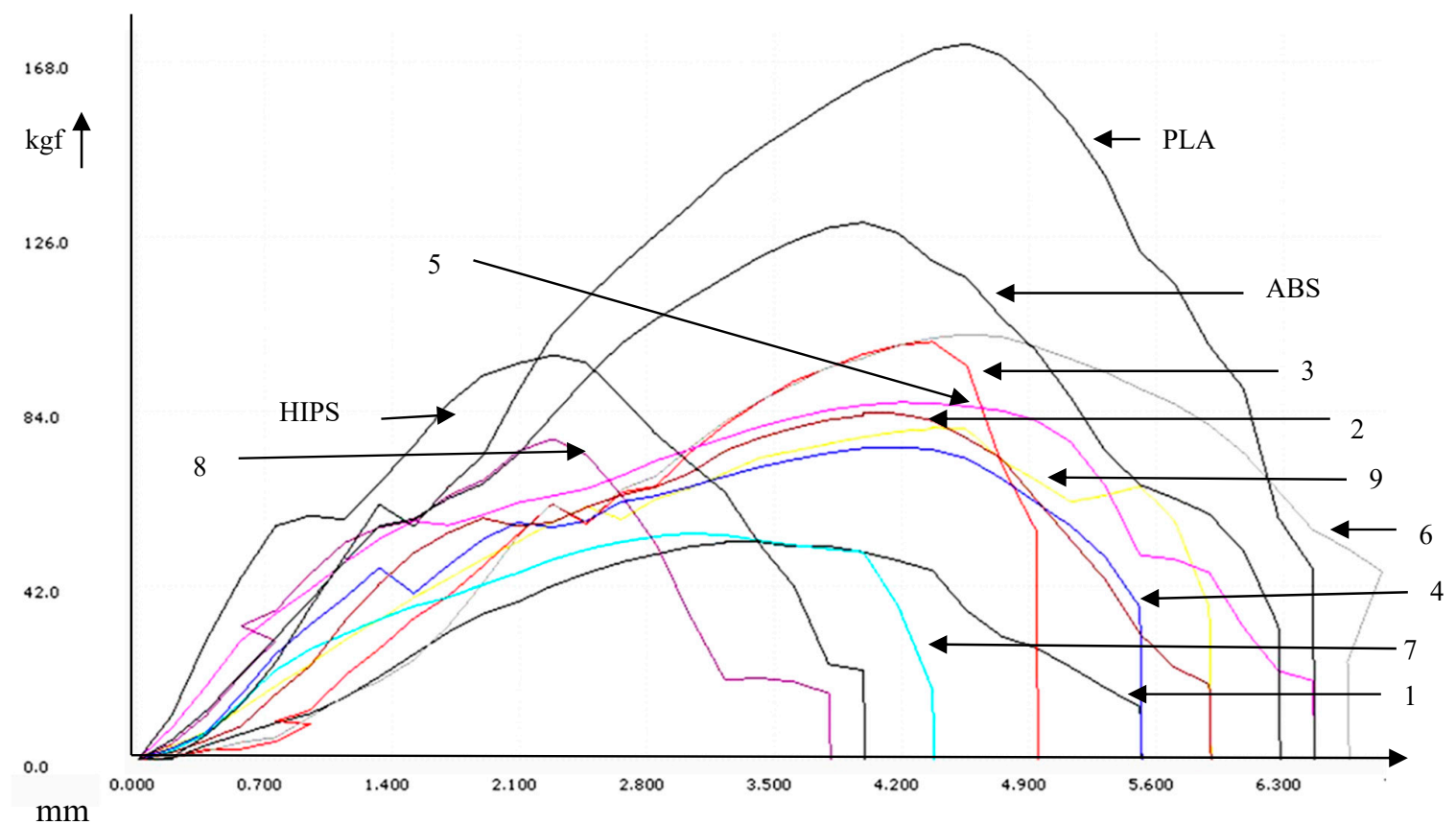

Figure 8. Load vs. deflection curves for multi-material components.

\section{Concluding Remarks}

The conclusions from the present study are as follows:

Multi-material 3D printing of recycled ABS, PLA, and HIPS polymers is feasible because these thermoplastics possess similar heat capacities $(13.63 \mathrm{~mJ}$ for ABS, $14.71 \mathrm{~mJ}$ for PLA, and $11.71 \mathrm{~mJ}$ for HIPS).

Tensile properties investigation revealed that the peak strength of HIPS (4.21 MPa) was the lowest of the materials. However, 3D printing of multi-materials resulted in a significant improvement of the tensile strength (10.78 MPa) under controlled input conditions.

It was observed from the pull-out test that the peak strength of HIPS $\left(27.4 \mathrm{~kg} / \mathrm{mm}^{2}\right)$ was the lowest of the materials, but multi-material 3D printing of HIPS with ABS and PLA increased its value to $28.81 \mathrm{~kg} / \mathrm{mm}^{2}$ (at best settings).

Overall, it can be concluded that multi-material printing of various thermoplastics is feasible for functional prototypes and can lead to improvement of their mechanical properties. In light of the structural applications of multi-materials, the future scope lies in the selection of various materials comprising the inner layer (with better compression properties), neutral layers (with moderate compression and tensile properties), and outermost layers (with better tensile properties) selected as per tailor-made requirements. In other words, the limited mechanical properties of some thermoplastics can be used as an advantage in multi-material functional prototypes, e.g., in mechanical meta-materials combining soft and hard modes [8,20]. Moreover, such materials can be also employed to print recycled reinforcing elements to be embedded in an epoxy resin matrix [39] or in a mortar or concrete matrix in order to realize sustainable composite materials [40-50].

With advancements in smart materials for $4 \mathrm{D}$ printing and self-assembly applications, multi-material 3D printing can overcome the shortcomings of single materials. Compared to single-material 3D printing, multi-material 3D printing gives more flexibility to functional prototypes (with totally different/enhanced multi-dimensional properties), which basically reduces the required mass of the component and hence the material requirement under different loading conditions. This will help to print more complicated components and to reduce waste.

Author Contributions: R.S. has participated in drafting the article, in giving final approval of the version to be submitted and he has supervised the preparation of the specimens, the execution of DSC tests, and micrographic 
observations. R.K. has led the preparation of the specimens, the execution of DSC tests, and micrographic observations. I.F. has led the execution of mechanical tests, has collaborated to micrographic observations and has contributed to the writing of the manuscript. F.C. has contributed to the interpretation of mechanical tests and of micrographic observations. L.F. has supervised the execution of mechanical tests. F.F. has provided the topic and the motivation, and has co-supervised the work carried out by all authors.

Acknowledgments: R.S. and R.K. are highly thankful to Board of research in nuclear science (BRNS) No. 34/14/10/2016-BRNS/34040 and manufacturing research lab (GNDEC, Ludhiana) for providing financial/technical assistance to carry out the research work. I.F. gratefully acknowledges financial support from the Department of Engineering of the University of Naples "Parthenope". L.F. and F.F. acknowledge financial support from the Italian Ministry of Education, University and Research (MIUR) under the 'Departments of Excellence' grant L.232/2016.

Conflicts of Interest: The authors declare that the research was conducted in the absence of any commercial or financial relationships that could be construed as a potential conflict of interest.

\section{References}

1. Liu, C.; Huang, N.; Xu, F.; Tong, J.; Chen, Z.; Gui, X.; Fu, Y.; Lao, C. 3D printing technologies for flexible tactile sensors toward wearable electronics and electronic skin. Polymers 2018, 10, 629. [CrossRef]

2. Wang, G.; Cheng, A.H.D.; Ostoja-Starzewski, M.; Al-Ostaz, A.; Radziszewski, P. Hybrid lattice particle modelling approach for polymeric materials subject to high strain rate loads. Polymers 2010, 2, 3-30. [CrossRef]

3. Amendola, A.; Nava, E.H.; Goodall, R.; Todd, I.; Skelton, R.E.; Fraternali, F. On the additive manufacturing, post-tensioning and testing of bi-material tensegrity structures. Compos. Struct. 2015, 131, 66-71. [CrossRef]

4. Amendola, A.; Smith, C.J.; Goodall, R.; Auricchio, F.; Feo, L.; Benzoni, G.; Fraternali, F. Experimental response of additively manufactured metallic pentamode materials confined between stiffening plates. Compos. Struct. 2016, 142, 254-262. [CrossRef]

5. Kadic, M.; Bückmann, T.; Stenger, N.; Thiel, M.; Wegener, M. On the practicability of pentamode mechanical metamaterials. Appl. Phys. Lett. 2012, 100, 191901. [CrossRef]

6. Mao, Y.; Miyazaki, T.; Sakai, K.; Gong, J.; Zhu, M.; Ito, H. A 3D Printable Thermal Energy Storage Crystalline Gel Using Mask-Projection Stereolithography. Polymers 2018, 10, 1117. [CrossRef]

7. Meza, L.R.; Das, S.; Greer, J.R. Strong, lightweight, and recoverable three-dimensional ceramic nanolattices. Science 2014, 345, 1322-1326. [CrossRef]

8. Schittny, M.; Bückmann, T.; Kadic, M.; Wegener, M. Elastic measurements on macroscopic three-dimensional pentamode metamaterials. Appl. Phys. Lett. 2013, 103, 231905. [CrossRef]

9. Truby, R.L.; Lewis, J.A. Printing soft matter in three dimensions. Nature 2016, 540, 371-378. [CrossRef]

10. Yuan, S.; Bai, J.; Chua, C.K.; Wei, J.; Zhou, K. Material evaluation and process optimization of CNT-coated polymer powders for selective laser sintering. Polymers 2016, 8, 370. [CrossRef]

11. Zheng, X.; Lee, H.; Weisgraber, T.H.; Shusteff, M.; DeOtte, J.; Duoss, E.B.; Kuntz, J.D.; Biener, M.M.; Ge, Q.; Jackson, J.A.; et al. Ultralight, ultrastiff mechanical metamaterials. Science 2014, 344, 1373-1377. [CrossRef] [PubMed]

12. Singh, R.; Kumar, R.; Ranjan, N. Sustainability of Recycled ABS and PA6 by Banana Fiber Reinforcement: Thermal, Mechanical and Morphological Properties. J. Inst. Eng. (India) Ser. C 2018, 1-10. [CrossRef]

13. Singh, R.; Kumar, R.; Feo, L.; Fraternali, F. Friction welding of dissimilar plastic/polymer materials with metal powder reinforcement for engineering applications. Compos. Part B Eng. 2016, 101, 77-86. [CrossRef]

14. Fabbrocino, F.; Farina, I.; Amendola, A.; Feo LFraternali, F. Optimal design and additive manufacturing of novel reinforcing elements for composite materials. In Proceedings of the ECCOMAS Congress 2016-European Congress on Computational Methods in Applied Sciences and Engineering, Crete Island, Greece, 5-10 June 2016.

15. Kumar, R.; Singh, R.; Ahuja, I.P.S.; Amendola, A.; Penna, R. Friction welding for the manufacturing of PA6 and ABS structures reinforced with Fe particles. Compos. Part B Eng. 2018, 132, 244-257. [CrossRef]

16. Kumar, R.; Singh, R.; Ahuja, I.P.S.; Penna, R.; Feo, L. Weldability of thermoplastic materials for friction stir welding-A state of art review and future applications. Compos. Part B Eng. 2017, 137, 1-15. [CrossRef]

17. Kumar, R.; Singh, R.; Hui, D.; Feo, L.; Fraternali, F. Graphene as biomedical sensing element: State of art review and potential engineering applications. Compos. Part B Eng. 2017, 134, 193-206. [CrossRef] 
18. Singh, R.; Kumar, R.; Mascolo, I.; Modano, M. On the applicability of composite PA6-TiO 2 filaments for the rapid prototyping of innovative materials and structures. Compos. Part B Eng. 2018, 143, 132-140. [CrossRef]

19. Singh, R.; Kumar, R.; Ranjan, N.; Penna, R.; Fraternali, F. On the recyclability of polyamide for sustainable composite structures in civil engineering. Compos. Struct. 2018, 184, 704-713. [CrossRef]

20. Kumar, R.; Singh, R.; Farina, I. On the multi-material 3D printing of recycled ABS, PLA and HIPS thermoplastics for structural applications. PSU Res. Rev. 2018, 2, 115-137. [CrossRef]

21. Bandyopadhyay, A.; Heer, B. Additive manufacturing of multi-material structures. Mater. Sci. Eng. R Rep. 2018, 129, 1-16. [CrossRef]

22. Guessasma, S.; Nouri, H.; Roger, F. Microstructural and mechanical implications of microscaled assembly in droplet-based multi-material additive manufacturing. Polymers 2017, 9, 372. [CrossRef]

23. Muguruza, A.; Bo, J.B.; Gómez, A.; Minguella-Canela, J.; Fernandes, J.; Ramos, F.; Cirera, A. Development of a multi-material additive manufacturing process for electronic devices. Procedia Manuf. 2017, 13, 746-753. [CrossRef]

24. Ngo, T.D.; Kashani, A.; Imbalzano, G.; Nguyen, K.T.; Hui, D. Additive manufacturing (3D printing): A review of materials, methods, applications and challenges. Compos. Part B Eng. 2018, 143, 172-196. [CrossRef]

25. Lee, J.Y.; An, J.; Chua, C.K. Fundamentals and applications of 3D printing for novel materials. Appl. Mater. Today 2017, 7, 120-133. [CrossRef]

26. Momeni, F.; Liu, X.; Ni, J. A review of 4 D printing. Mater. Des. 2017, 122, 42-79. [CrossRef]

27. Ma, R.R.; Belter, J.T.; Dollar, A.M. Hybrid deposition manufacturing: Design strategies for multi material mechanisms via three-dimensional printing and material deposition. J. Mech. Robot. 2015, 7, 021002. [CrossRef]

28. Bittner, S.M.; Guo, J.L.; Melchiorri, A.; Mikos, A.G. Three-dimensional printing of multilayered tissue engineering scaffolds. Mater. Today 2018, 21, 861-874. [CrossRef]

29. Mohammed, M.; Tatineni, J.; Cadd, B.; Peart, P.; Gibson, I. Applications of 3D topography scanning and multi-material additive manufacturing for facial prosthesis development and production. In Proceedings of the 27th Annual International Solid Freeform Fabrication Symposium, Austin, TX, USA, 8-10 August 2016; pp. 1695-1707.

30. Meisel, N.A. Design for Additive Manufacturing Considerations for Self-Actuating Compliant Mechanisms Created via Multi-Material PolyJet 3D Printing. Ph.D. Thesis, Virginia Polytechnic Institute and State University, Blacksburg, VA, USA, 2015; pp. 1-272.

31. Vu, I.Q.; Bass, L.B.; Williams, C.B.; Dillard, D.A. Characterizing the effect of print orientation on interface integrity of multi-material jetting additive manufacturing. Addit. Manuf. 2018. [CrossRef]

32. Rutkowski, J.V.; Levin, B.C. Acrylonitrile-butadiene-styrene copolymers (ABS): Pyrolysis and combustion products and their toxicity-A review of the literature. Fire Mater. 1986, 10, 93-105. [CrossRef]

33. Singh, R.; Sandhu, G.S.; Penna, R.; Farina, I. Investigations for thermal and electrical conductivity of ABS-graphene blended prototypes. Materials 2017, 10, 881. [CrossRef]

34. Martin, O.; Averous, L. Poly (lactic acid): Plasticization and properties of biodegradable multiphase systems. Polymer 2001, 42, 6209-6219. [CrossRef]

35. Singh, D.; Singh, R.; Boparai, K.S.; Farina, I.; Feo, L.; Verma, A.K. In-vitro studies of SS 316 L biomedical implants prepared by FDM, vapor smoothing and investment casting. Compos. Part B Eng. 2018, 132, 107-114. [CrossRef]

36. Torres, J.; Cotelo, J.; Karl, J.; Gordon, A.P. Mechanical property optimization of FDM PLA in shear with multiple objectives. JOM 2015, 67, 1183-1193. [CrossRef]

37. Farbman, D.; McCoy, C. Materials Testing of 3D Printed ABS and PLA Samples to Guide Mechanical Design. In Proceedings of the ASME 2016 11th International Manufacturing Science and Engineering Conference, Blacksburg, VA, USA, 27 June-1 July 2016; p. V002T01A015.

38. Aw, Y.Y.; Yeoh, C.K.; Idris, M.A.; Teh, P.L.; Hamzah, K.A.; Sazali, S.A. Effect of printing parameters on tensile, dynamic mechanical and thermoelectric properties of FDM 3D printed CABS/ZnO composites. Materials 2018, 11, 466. [CrossRef] [PubMed]

39. Ricciotti, L.; Roviello, G.; Tarallo, O.; Borbone, F.; Ferone, C.; Colangelo, F.; Cioffi, R. Synthesis and characterizations of melamine-based epoxy resins. Int. J. Mol. Sci. 2013, 14, 18200-18214. [CrossRef] [PubMed] 
40. Colangelo, F.; Petrillo, A.; Cioffi, R.; Borrelli, C.; Forcina, A. Life cycle assessment of recycled concretes: A case study in southern Italy. Sci. Total Environ. 2018, 615, 1506-1517. [CrossRef] [PubMed]

41. Coppola, L.; Bellezze, T.; Belli, A.; Bignozzi, M.C.; Bolzoni, F.; Brenna, A.; Carsana, M. Binders alternative to Portland cement and waste management for sustainable construction-Part 1. J. Appl. Biomater. Funct. Mater. 2018, 16, 186-202.

42. Migliaccio, M.; Ferrara, G.; Gifuni, A.; Sorrentino, A.; Colangelo, F.; Ferone, C.; Messina, F. Shielding effectiveness tests of low-cost civil engineering materials in a reverberating chamber. Prog. Electromagn. Res. 2013, 54, 227-243. [CrossRef]

43. Colangelo, F.; Messina, F.; Di Palma, L.; Cioffi, R. Recycling of non-metallic automotive shredder residues and coal fly-ash in cold-bonded aggregates for sustainable concrete. Compos. Part B Eng. 2017, 116, 46-52. [CrossRef]

44. Farina, I.; Fabbrocino, F.; Colangelo, F.; Feo, L.; Fraternali, F. Surface roughness effects on the reinforcement of cement mortars through 3D printed metallic fibers. Compos. Part B Eng. 2016, 99, 305-311. [CrossRef]

45. Colangelo, F.; Messina, F.; Cioffi, R. Recycling of MSWI fly ash by means of cementitious double step cold bonding pelletization: Technological assessment for the production of lightweight artificial aggregates. J. Hazard. Mater. 2015, 299, 181-191. [CrossRef] [PubMed]

46. Colangelo, F.; Cioffi, R.; Liguori, B.; Iucolano, F. Recycled polyolefins waste as aggregates for lightweight concrete. Compos. Part B Eng. 2016, 106, 234-241. [CrossRef]

47. Colangelo, F.; Cioffi, R. Mechanical properties and durability of mortar containing fine fraction of demolition wastes produced by selective demolition in South Italy. Compos. Part B Eng. 2017, 115, 43-50. [CrossRef]

48. Messina, F.; Ferone, C.; Colangelo, F.; Cioffi, R. Low temperature alkaline activation of weathered fly ash: Influence of mineral admixtures on early age performance. Constr. Build. Mater. 2015, 86, 169-177. [CrossRef]

49. Messina, F.; Ferone, C.; Molino, A.; Molino, B.; Cioffi, R. Synergistic recycling of calcined clayey sediments and water potabilization sludge as geopolymer precursors: Upscaling from binders to precast paving cement-free bricks. Constr. Build. Mater. 2017, 133, 14-26. [CrossRef]

50. Roviello, G.; Menna, C.; Tarallo, O.; Ricciotti, L.; Messina, F.; Ferone, C.; Asprone, D.; Cioffi, R. Lightweight geopolymer-based hybrid materials. Compos. Part B Eng. 2017, 128, 225-237. [CrossRef]

(C) 2019 by the authors. Licensee MDPI, Basel, Switzerland. This article is an open access article distributed under the terms and conditions of the Creative Commons Attribution (CC BY) license (http://creativecommons.org/licenses/by/4.0/). 